DOI: https://doi.org/10.47405/mjssh.v6i10.1082

\begin{tabular}{|c|c|}
\hline 4.581 & Malaysian Journal of Social Sciences and Humanities (MJSSH) \\
\hline $\begin{array}{l}\text { Malaysian Journal of } \\
\text { Social cciences and }\end{array}$ & Volume 6, Issue 10, October 2021 \\
\hline (MJ-SSH) & e-ISSN : 2504-8562 \\
\hline & $\begin{array}{l}\text { Journal home page: } \\
\text { www.msocialsciences.com }\end{array}$ \\
\hline
\end{tabular}

\title{
Identifying Students' Needs Towards the Provision of Social Support in Online Learning
}

\author{
Juhazren Junaidi ${ }^{1}$, Zaidatun Tasir ${ }^{1}$ \\ ${ }^{1}$ Faculty of Social Sciences and Humanities, Universiti Teknologi Malaysia (UTM), Malaysia \\ Correspondence: Juhazren bin Junaidi (juhazren@utm.my)
}

\begin{abstract}
Social support has been found to play an important role in retaining learning and contribute to better understanding and performance among students. This study aims to determine the needs and requirements of learners or students towards the provision of social support in online learning. Random sampling technique was used to select 10 students enrolled in an ICT-based course at one of Malaysian university as respondents. The instrument for this study was a semi-structured interview questions adapted from the works of Sarason et al. (1987). Thematic analysis was performed on the transcribed interview to allow visual interpretation and understanding of the context from each response. This study found that the students had often received and prefer to get social support while learning online. The reasons for their preference were for motivation, understanding, information searching and affirmation. The students were also identified to have preference for social support from the instructor more than from peers and the learning content. Overall, Informational Support is the most expected type of social support by the students. This study provides findings that would assist in the provision of social support through the design and development of an online learning environment.
\end{abstract}

Keywords: online learning, social support, online interaction

\section{Introduction}

Learning has become more cost effective and convenient through online learning, apart from the ability to perform learning asynchronously while being at the different time and place as the instructor (Richardson \& Swan, 2003; Paechter, Maier \& Macher, 2009). The imperative need to collaborate (Gomez-Lanier, 2018) and participate (Stone, 2017) among the next generation of learners, which is the trend of today (Curtis \& Lawson, 2001; Nigam, 2018) are achievable by using ICT as tools. Moore and Kearsley (2011) stated that online learning provides access to a richer learning environment and a more structured learning and dialogue through interaction using ICT. It can be understood that the participation of teachers or instructors and their students in an online interaction allows the formation of understanding thus enable learning to occur.

Cognition or thinking process in learning could be achieved by engaging the environment and exploiting the various resources around it (Pea, 2004). The learners require interaction with others, whether human or non-human (Hill, Song \& West, 2009) through online learning which will enhance the students' cognitive development when they work together in a collaborative environment (GomezLanier, 2018; Brook \& Oliver, 2002). Besides that, the form of usability that was brought into learning through online learning had shifted the overall teaching and learning process and opened a wide area to 
look at in providing better use and outcomes of ICT towards learning (Conole et al., 2008). Students of today, which Oblinger and Oblinger (2005) called the 'net generation' are found to be much more technology-savvy and are comfortable with it. They are found to be able of accessing and processing information much more quickly and capable of multi-tasking. The ability that the students nowadays have, requires them to socialize and collaborate with the support of technology to engage and perform better in learning (Oblinger \& Oblinger, 2005; de Laat, 2006). However, apart from the technology itself, another factor within the online interactions which is social support, further engage the students in online learning.

\section{Literature Review}

Technologies had emerged and shifted the nature and environment of open and distance education by providing ways for communities of learners and their teachers to interact with one another although being at different locations (Wilson \& Stacey, 2004). Online interaction is also increasingly being introduced into a flexible model of learning for higher education institution learners. Research has shown that electronic interactions through online environment can be structured for effective learning through interactive online discussions (Wan Hussin et al., 2019; Stacey, 2002; Bonk \& Cunningham, 1998). Besides having technology as a mediator in the online interaction, the effectiveness of the interaction itself is important (Moore, 1989; Garrison \& Cleveland-Ines, 2005). Students were found to learn more effectively when active approaches are applied allowing them to communicate, interact and engage with others (Hiltz, 1998; Henning, 2004). Through regular online interaction, students could learn very effectively although being at a distance (Stacey, 1999). Wilson and Stacey (2003) noted that it is important to structure and facilitate effective online learning experience and help to establish an online learning community among the students.

Online interactions will also need to be meaningful, which Vrasidas and McIsaac (1999) defined as "the intellectually stimulating exchange of ideas". Online interactions should go beyond regular social interaction and the simple exchange of information by including various combinations of interaction and reflection among content, teachers, and students, thus a more structured and systematic interaction will be required (Jeong \& Frazier, 2008). Moore (1989) defined interaction based upon a communication-based framework, defining the sender and receiver of three types of interaction: learner-content, learner-instructor, and learner-learner. In learning, the three modes of interaction need to function cohesively in practice. Apart from the types, it is equally important to focus on forms of online interaction flexibility in which the interaction takes place between instructor-learner, learnerlearner, and learner-content with the mediation of technology (Hillman, Willis \& Gunawardena, 1994; Garrison \& Anderson, 1998).

In accommodating the intense growth of online social interaction, it was found that another component is needed to ensure positive online social interaction which is social support (Copeland \& Norell, 2002). Social Support has been defined broadly as "the availability of helping relationships and the quality of relationships" (Leavy, 1983). Sufficient social support would help in reducing stress in learning among students (Misra \& McKean, 2000; Sawir, et al., 2008). Ye (2006) stated that social support can be delivered through online interaction, provided that the students are engaged with the right form of interaction. According to Pornsakulavich (2017), social support satisfaction has a strong relationship with students' amount of online interaction. Social support also played an important role in retaining learning and contribute to better understanding and performance. Hsiao, Brouns and Sloep (2012) stated that without social support, knowledge sharing does not occur, while simultaneusly increases cognitive load. Keane et al. (2008) mentioned a similar note on students' performance where their success depends highly on their ability to engage in the online learning environment. According to House (1981), social support in the context of reducing students' stress in learning includes (a) emotional support, (b) informational support, (c) instrumental support, and (d) affirmational support. While social support was found to be important in online learning environments, as well as has significant implication towards students' performance, it is equally important to conduct a deeper study on the preference of online social support among students. 


\section{Objectives of Study}

The objectives for this study are:

i. To identify students' preference towards the provision of social support in online learning

ii. To analyze the reason of preference towards online social support

iii. To identify students' preferred source of online social support

iv. To identify students' preferred type of online social support

\section{Questions of Study}

This study poses the questions:

i. Do students prefer to receive social support while learning online?

ii. What are the reasons for students' preference towards social support in online learning?

iii. What are the students' preferred source of online social support?

iv. What are the students' preferred type of online social support?

\section{Method of Study}

This study was performed as an exploratory study to seek understanding on students' preference towards online social support. This study serves as a needs analysis for the design of an online learning environment that would provide social support to students. A semi-structured interview questions have been developed by adopting the work of Sarason et al. (1987), Social Support Questionnaire Short Form (SSQSR). A previous study reported the SSQSR with a reliability of $\boldsymbol{\alpha}=0.92$ (Dumrongsiri and Pornsakulavich, 2010).

The respondents for this study were selected from a group of 29 students enrolled in an ICT-based course at one of Malaysian university. Using the random sampling technique, 10 students from the group were selected as respondents. Thematic analysis was performed on the interview transcripts. During analysis, data were contextualized and extracted from the interview transcripts. The data were grouped according to similarity where the data then being assign to themes and sub-themes that represent the meaning which will be described quantitatively (Braun \& Clarke, 2006). The pattern from the data will then be identified and be utilized to produce a sound conclusion of the study.

\section{Findings of Study}

\section{Students Prefer to Receive Social Support while Learning Online}

One of the objectives of this study is to confirm the participants are aware of online social support and their preference towards the support. Before starting with the interview questions, the respondents were briefed on the definition of social support and the types within the context of this study. The respondents were then asked if they had often received social support while learning online. 9 respondents acknowledged that they often received social support while learning online, and the other respondent received less. When being asked for the reason being so, the one respondent mentioned:

"Online learning provided me with less social support due to the non-face-to-face learning process while having less communication between the instructor and students" (S1).

On a positive note, a respondent which had often received social support commented: 
"I often receive social support and gave some as well towards my peers. The lecturer also assisted us if we needed more clarification (in learning) and always provided guidance as good as possible until i understand" (S5).

The respondents were asked if they prefer to get social support while learning online. The responses given indicated that they prefer to get social support while learning online. The respondents were further asked on their satisfaction towards the social support that have been received. All the respondents were satisfied with the social support they received when learning online.

\section{Reasons Behind Students' Preference Towards Online Social Support}

The respondents were also asked on the reasons behind their preference towards receiving social support while learning online. Out of the 10 respondents, 4 had provided with more than one reason. Table 1 shows the reasons given by each of the respondents.

Table 1: Responses According to Students

\begin{tabular}{ccccc}
$\begin{array}{c}\text { Student } \\
\text { (S) }\end{array}$ & Understanding & Motivation & $\begin{array}{c}\text { Information } \\
\text { Searching }\end{array}$ & Affirmation \\
\hline S1 & $\checkmark$ & & & \\
S2 & $\checkmark$ & $\checkmark$ & $\checkmark$ & \\
S3 & $\checkmark$ & $\checkmark$ & & \\
S4 & & $\checkmark$ & & \\
S5 & $\checkmark$ & $\checkmark$ & & \\
S6 & $\checkmark$ & $\checkmark$ & & \\
S7 & & $\checkmark$ & & $\checkmark$ \\
S8 & & $\checkmark$ & & \\
S9 & & 7 & 1 & 1 \\
S10 & & 5 & & \\
\hline Total & & & & \\
\hline
\end{tabular}

From the responses given by the respondents, it was found out that the given reasons were as follows: 5 responses stated 'understanding', 7 responses for 'motivation', 1 noted 'information searching', and 1 mentioned 'affirmation'. Therefore, it can be concluded here that motivation and understanding are the main reasons why students need social support. However, students also need social support for information searching and affirmation while learning online. Figure 1 shows the distribution of students' responses.

Figure 1: Reasons for Student's Preference of Social Support

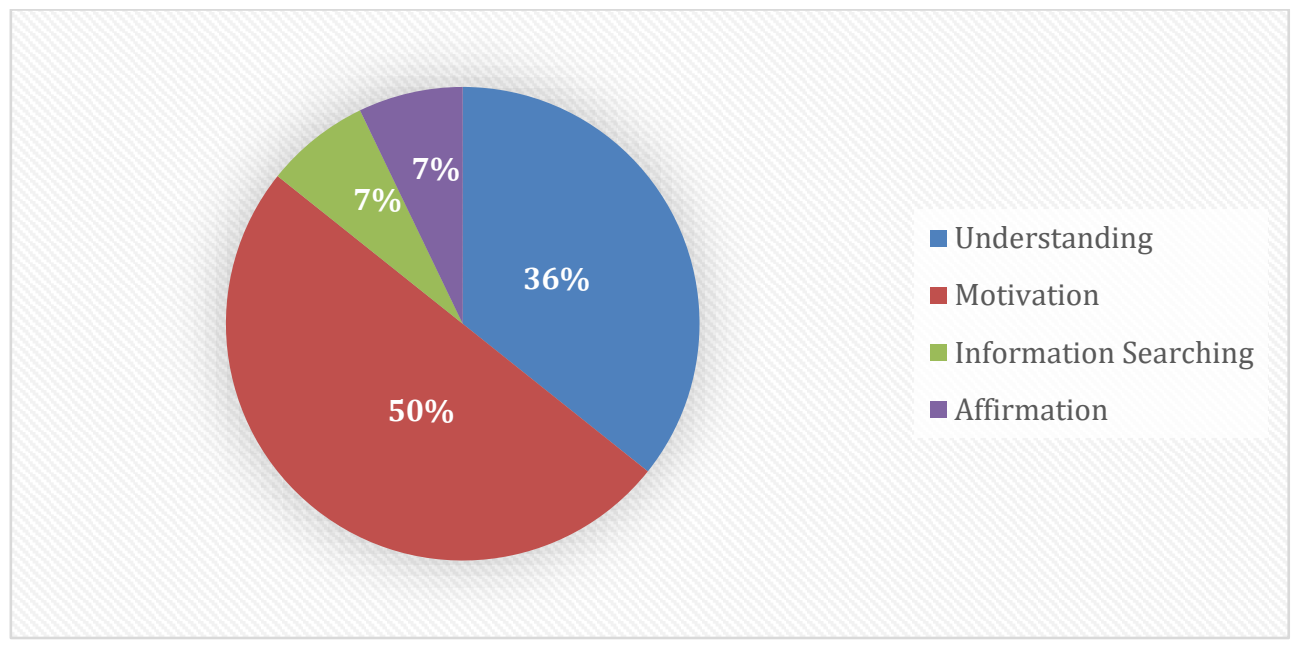


DOI: https://doi.org/10.47405/mjssh.v6i10.1082

\section{Students Preferred Source of Online Social Support.}

The next question had introduced the interviewees to the types of interaction which serves as the three main sources of social support according to Moore (1989). Then, based on their experience and preference, the respondents were asked to rank the three sources of social support. Table 2 depicts the responses from the interviewees.

Table 2: Rank of Source of Social Support According to Student's Preference

\begin{tabular}{cccc}
\hline Student & Peers & Instructor & Content \\
\hline S1 & 2 & 1 & 3 \\
S2 & 2 & 1 & 3 \\
S3 & 3 & 1 & 2 \\
S4 & 1 & 3 & 2 \\
S5 & 3 & 1 & 2 \\
S6 & 2 & 1 & 3 \\
S7 & 1 & 2 & 3 \\
S8 & 3 & 1 & 2 \\
S9 & 3 & 2 & 1 \\
S10 & 2 & 1 & 3 \\
\hline
\end{tabular}

From the data in Table 2, it was found that the respondents have preference for social support from the instructor more than from peers and the learning content. The reason would mainly due to the instructor as the primary source of learning or information. This can be observed from the number of responses given, where 7 respondents had ranked the instructor as their number one source of social support. There are 2 respondents that ranked peers as their number one source of social support, while only one ranked the learning content as number one.

Table 2 also indicated that the preference of social support from peers and learning content seemed balanced. However, peers have the advantage over content as number one source of social support where 2 respondents ranked peers as number one source as compared to only one for content. There are 4 respondents that ranked both peers and content as their second preferred source of social support, while 2 respondents ranked the instructor as second. As for the third preference, only one respondent ranked instructor, 4 ranked peers and 5 respondents ranked content.

\section{Students Preferred Type of Online Social Support}

The respondents were further asked on the types or forms of social support that are expected from the mentioned sources. Table 3 provides the summary from the interviews.

Table 3: Types of Preferred Social Support from Sources

\begin{tabular}{|c|c|c|c|c|c|c|c|c|c|c|c|c|}
\hline & \multicolumn{4}{|c|}{ Peers } & \multicolumn{4}{|c|}{ Instructor } & \multicolumn{4}{|c|}{ Content } \\
\hline Student & ES & $\mathbf{A S}$ & InfS & InS & $\mathbf{E S}$ & $\mathbf{A S}$ & InfS & InS & ES & $\mathbf{A S}$ & InfS & InS \\
\hline S1 & $\checkmark$ & & & $\checkmark$ & $\vee$ & $\checkmark$ & $\checkmark$ & $\checkmark$ & & & $\checkmark$ & $\checkmark$ \\
\hline S2 & $\checkmark$ & & $\checkmark$ & $\checkmark$ & $\checkmark$ & & $\checkmark$ & $\checkmark$ & & & $\checkmark$ & \\
\hline S3 & $\checkmark$ & & & & & & $\checkmark$ & & & & & $\checkmark$ \\
\hline S4 & $\checkmark$ & $\vee$ & & & & $\checkmark$ & $\vee$ & $\checkmark$ & & & $\checkmark$ & $\checkmark$ \\
\hline S5 & $\checkmark$ & $\checkmark$ & $\checkmark$ & $\vee$ & $\vee$ & $\checkmark$ & $\checkmark$ & $\checkmark$ & & & $\checkmark$ & \\
\hline S6 & & & $\checkmark$ & $\checkmark$ & & $\checkmark$ & $\checkmark$ & $\checkmark$ & & & $\checkmark$ & \\
\hline
\end{tabular}




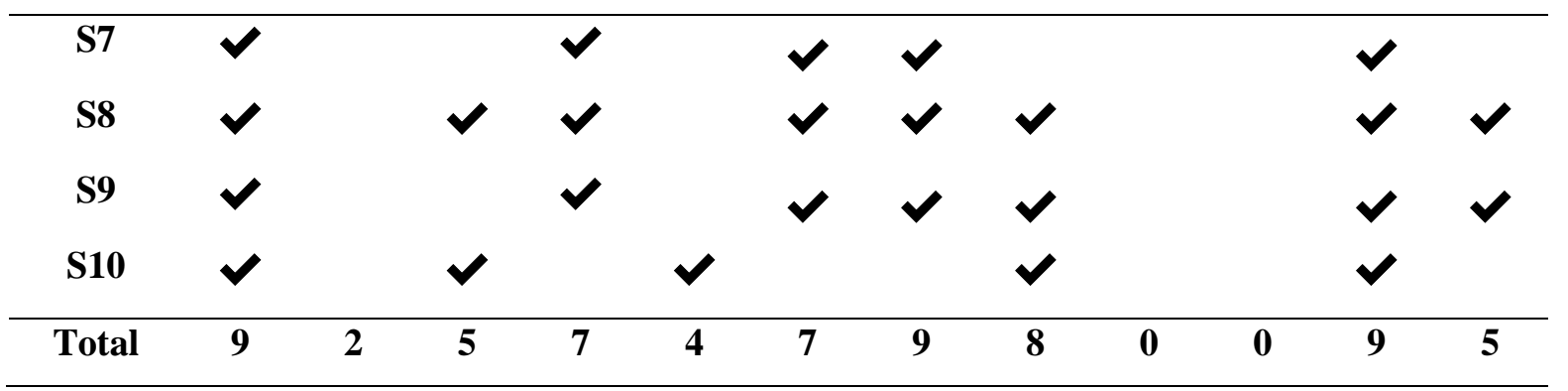

*ES: Emotional Support, AS: Affirmational Support, InfS: Informational Support, InsS: Instrumental Support.

It can be observed that the types or forms of social support that are expected from the mentioned sources are mostly Informational Support (InfS). The respondents gave 9 responses for InfS from the instructor, another 9 responses for the learning content, and 5 responses for peers. The second expected type of social support as responded was Instrumental Support (InsS) where there are 8 responses for instructor, 7 responses for peers, and 5 for learning content.

Emotional Support (ES) is the third expected type of social support with 9 responses for peers and 4 responses for instructors. The respondents also expected Affirmational Support (AS) from the instructor with 7 responses, while peers had 2 responses. There were no recorded responses for ES and AS from the respondents for learning content.

\section{Discussion of Findings}

From the analysis, it can be summarized that all students prefer to get social support while learning online. The reasons for their preference was for motivation, understanding, information searching and affirmation. The students were also identified to have preference for social support from the instructor more than from peers and the learning content. Overall, Informational Support (InfS) is the most expected type of social support by the students, while Instrumental Support (InsS) was identified as second. Emotional Support (ES) is the third expected type of social support, followed by Affirmational Support (AS). The interview also indicated that 9 out of 10 students often received social support while learning online.

The students had indicated that they received most of the social support from their peers apart from the instructor. This finding is slightly different from the data shown in Table 2 . The needs analysis interview had also discovered that from their peers, the students had received mostly ES, followed by InfS, then AS and InsS. From the instructor, the students had mostly received AS and InfS, then ES and InsS. The students stated that they are fairly satisfied with the social support that they had received. They also explained that the reason they were satisfied with the received social support was to support their learning process, as well as their emotions. The students also needed affirmation and social presence, which could be provided through interaction in the learning process.

\section{Conclusion}

As a conclusion to this exploratory study, there are four main findings that can be made. Firstly, the students were found to have preference for receiving social support while learning online. Furthermore, they were satisfied with the online social support that they have received. Secondly, the reasons behind the students' preferring to receive online social support was mainly related to their emotional well being and understanding. Third, students were found to have received most online social support from peers although they expected instructors to provide them with most of it. And lastly, the types of online social support expected by the students are Informational, Instrumental, Emotional and Affirmational. It is hoped from this study that instructors and instructional designers would take into consideration for social support to be provided during online learning sessions. 


\section{References}

Brook, C. and Oliver, R. (2002). Supporting The Development Of Learning Communities In Online Settings. ED-MEDIA 2002 World Conference on Educational Multimedia, Hypermedia \& Telecommunications. Proceedings (14th, Denver, Colorado, June 24-29, 2002); see IR 021687.

Conole, G., de Laat, M., Dillon, T., and Darby, J. (2008). 'Disruptive technologies', 'pedagogical innovation': What's new? Findings from an in-depth study of students' use and perception of technology. Computers \& Education, 50, 511-524.

Garrison, D.R. and Cleveland-Ines, M. (2005). Facilitating Cognitive Presence In Online Learning: interaction Is Not Enough. The American Journal of Online Learning, 19(3), 133-148.

Gomez-Lanier, L. (2018). Building Collaboration in the Flipped Classroom: A Case Study. International Journal for the Scholarship of Teaching \& Learning, 12(2), 1-9, [online] Available: https://doi-org.ezproxy.hct.ac.ae/10.20429/ijsotl.2018.120207.

Henning, W. (2004). Everyday cognition and situated learning. In Handbook of research on educational communications and technology, 2nd, Edited by: Jonassen, D. 143-168. Mahwah, NJ: Erlbaum.

Hill, J.R., Song, L. \& West, R. E. (2009) Social Learning Theory and Web-Based Learning Environments: A Review of Research and Discussion of Implications, The American Journal of Distance Education, 23(2), 88-103.

Hillman, D. C., Willis, D. J. and Gunawardena, C. N. (1994). Learner-Interface Interaction in Distance Education: An Extension of Contemporary Models and Strategies for Practitioners. The American Journal of Distance Education, 8(2), 30-42.

House, J. S. (1981). Work Stress and Social Support. Massachusetts: Addison-Wesley.

Hsiao, Y. P., Brouns, F. and Sloep, P. B. (2012). Designing optimal peer support to alleviate learner cognitive load in Learning Networks. DSpace Open Universiteit, http://dspace.ou.nl/handle/1820/4220.

Leavy, R. L. (1983). Social Support and Psychological Disorder: A Review. Journal of Community Psychology, 11, 3-21.

Moore, M. G., and Kearsley, G. (2011). Distance education: A systems view of online learning. CengageBrain. com.

Nigam, S. (2018). Role of Online Education in Today's World. Online Education, 7(2), 5-8.

Paechter, M., Maier, B. and Macher, D. (2009). Students' expectations of, and experiences in elearning: Their relation to learning achievements and course satisfaction. Computers \& Education, 54, 222-229.

Pornsakulavich, V. (2017). Personality, attitudes, social influences, and social networking site usage predicting online social support. Computers in Human Behavior, 76, 255-262.

Sarason, I. G., Sarason, B. R., Shearin, E. N., \& Pierce, G. R. (1987). A brief measure of social support: Practical and theoretical implications. Journal of Social and Personal Relationships, 4, 497-510.

Stone, C. (2017). Opportunity Through Online Learning: Improving Student Access, Participation and Success in Higher Education (NCSEHE 2016 Equity Fellowship Final Report). Perth: Curtin University, National Centre for Higher Education. Retrieved from https://www.ncsehe.edu.au/publications/opportunity-online-learning-improving-student-accessparticipation-success-higher-education/

Vrasidas, C. and McIsaac, M. S. (1999). Factors Influencing Interaction in an Online Course. American Journal of Distance Education, 13(3), 22-36.

Wan Hussin, W. N. T., Harun, J. and Shukor, N. A. (2019). A Review on the Classification of Students' Interaction in Online Social Collaborative Problem-based Learning Environment: How Can We Enhance the Students' Online Interaction?. Universal Journal of Educational Research, 7 (9A), 125-134.

Wilson, G. and Stacey, E. (2004). Online interaction impacts on learning: Teaching the teachers to teach online. Australasian Journal of Educational Technology, 20(1), 33-48. 